\title{
The Role of Socio-demographic Variables, Sexual Relationship, Marital Stability, Marital Communication and Conflict Resolution in Marital Satisfaction Among Married Individuals in Addis Ababa, Ethiopia
}

\author{
Zewdu Girma \\ Psychology Department, Madda Walabu University, Bale Robe, Ethiopia
}

Email address:

zewdug42@yahoo.com

To cite this article:

Zewdu Girma. The Role of Socio-demographic Variables, Sexual Relationship, Marital Stability, Marital Communication and Conflict Resolution in Marital Satisfaction Among Married Individuals in Addis Ababa, Ethiopia. International Journal of Psychological and Brain Sciences. Vol. 9, No. 6, 2020, pp. 87-98. doi: 10.11648/j.pbs.20200906.11

Received: September 14, 2020; Accepted: September 27, 2020; Published: November 11, 2020

\begin{abstract}
Intact and harmonious marital relationships are required not only for the mental health of the individual but also for children and thus, for the society in the broader sense. But unsatisfying and stressful marital relations lead to increased emotional disturbances and marital disruption. This study aimed to assess the role of socio-demographic, sexual relationship, marital stability, marital communication and marital conflict resolution in marital satisfaction among married individuals. The target population for this study was all heterosexual married individuals, legally bound by the state of marriage as husband and wife. Quantitative research design and a systematic sampling technique along with a simple random sampling technique were employed to select 326 households. Frequency and percentages, means, standard deviations, Pearson correlation, independent sample T-test, one-way ANOVA, and hierarchical multiple linear regressions were all used to compute sample statistic. In the hierarchical multiple linear regression analysis, from the socio-demographic variables, only age and occupation type predicted significantly married individuals' marital satisfaction, $\mathrm{b}=-.13, \beta=-.08$ and $\mathrm{b}=7.37, \beta=.09$, respectively, $\mathrm{p}<.05$. The result implies that age has a negative impact whereas occupation type has a positive impact on the marital satisfaction of married individuals. Sexual relationships, marital stability, marital conflict resolution, and marital communication were significant predictors of marital satisfaction, with other variables held constant, at $\mathrm{p}<.001$. The most important predictors of marital satisfaction as the results of the study disclosed were sexual relationships followed by marital stability $(\mathrm{b}=.51, \beta=.28$, and $\mathrm{b}$ $=1.04, \beta=.27$, respectively, $\mathrm{p}<.001$ ). Together all the significant independent variables in the model accounted for $74 \%$ of the variance in married individuals' marital satisfaction and the model was significant, $\mathrm{F}(10,297)=45.83, \mathrm{p}<.001$. This study adds a sound, contextual and specific knowledge to the existing marriage counseling practices and theories as well to enhance or reduce factors for married individuals' marital satisfaction.
\end{abstract}

Keywords: Marital Satisfaction, Marital Stability, Marital Conflict Resolution, Sexual Satisfaction, Marital Communication, Multiple Linear Regression, Hierarchical Multiple Linear Regression Analysis

\section{Introduction}

Intact and harmonious marital relationships are required not only for the mental health of the individual but also for children and thus, for the society in the broader sense. However, unsatisfying and stressful marital relations lead to increased psychological disturbances and marital instability. A large literature shows that better marital satisfaction is associated with less depression, improved self-rated health, and less physical illness and stable marriage [1]. Marital satisfaction within the research literature refers to how happy or satisfied a person is in his or her relationship. It's a frequently studied aspect of relationships, however, there is little consensus on the definition of relationship satisfaction or the theory underpinning it [2]. Probably due to this lack of consensus, marital satisfaction is commonly used interchangeably with terms such as marital happiness, and 
marital quality, although these concepts are not synonymous. Dissimilarity is made between marital satisfaction and relationship quality. The former was a measure of an intrapersonal phenomenon (unidimensional) and the latter was both a measure of an interpersonal as well as an intrapersonal phenomenon. Marital satisfaction and happiness both refer to subjective evaluations of positive affect in the marital relationship by one (or both) of the spouses [3]. According to them [3], marital happiness is based on an affective evaluation, whereas marital satisfaction seems to have a more cognitive basis that involves a relation of one's circumstances to some standard.

The concept of marital satisfaction, not only among scholars, can vary across time and place with some aspects of marital satisfaction applying to some places or groups, but not to others [2]. For instance, the Dyadic Adjustment Scale developed in reference to an American sample poses the frequency of kissing as an aspect of marital satisfaction, but Shek and Cheung [4] reported that kissing is not a sign of marital satisfaction in China. Similarly, Lee and Ono [5] suggested that a good marriage in Japan is normally understood as one in which the husband works and the wife does not, while the husband's ability to support his wife is not as important in the conception of a good marriage in the United States. These contextual differences raise the challenge of developing measures of marital satisfaction that are relevant to a particular context, while also allowing for comparison across contexts.

Studies have shown that marital satisfaction is not so easily achieved [6] due to a wide range of both psychosocial and socio-demographic factors that could affect husband's and wife's behavior, thinking, feelings, communication, and other interpersonal interactions in marriage needed to be taken into account when assessing satisfaction in marriage. The scholars found different variables such as age, length of the marriage, education, employment status, number of marriages [7]; gender [7-9], absence/number of children [7, 10], relationship status $[11,12]$, personality traits [13-15], attachment $[16,17]$ and psychological problems $[18,19]$ to be associated with relationship satisfaction

Researches on marital satisfaction report significant dissimilarity between genders. In one study using a large sample from 1980 to 2000 concluded that wives reported a lower level of marital happiness than husbands [20]. Similarly, Basat [21] and Jose and Alfons [7] demonstrated that women report more marital problems than men, meaning that women tend to report lower relationship satisfaction than men. Additionally, Guo and Huang [22] showed men's level of relationship satisfaction to be higher than women's relationship satisfaction among married people. On the other hand, Renaud, Byers, \& Pan [8] stated that men and women do not differ in their relationship satisfaction. Similarly, Christensen et al. [23] also showed that gender is not a significant predictor for relationship satisfaction. Some researchers, such as Jose and Alfons [7] found that age has a negative impact on relationship satisfaction. The authors indicated that older individuals gain less satisfaction from their relationships. On the other hand, some researchers, such as Argyle and Furnham [24] have asserted that older individuals tend to report greater satisfaction from their relationships. However, Hill [25] indicated that there is no relationship between age and relationship satisfaction.

Like other socio-demographic variables, the association between relationship duration and satisfaction has been investigated by researchers. The study conducted by Moore, McCabe, and Brink [26] among dating, cohabiting and married individuals indicated that the longer individuals had been in their relationships, the higher the level of relationship satisfaction they experienced. On the contrary, Jose and Alfons [7] demonstrated that the length of marriage was negatively associated with relationship satisfaction. Similarly, the study conducted by Kurdek [27] showed that individuals reported a reduction in their relationship satisfaction over time. In addition to the socio-demographic variables, psychosocial variables like sexual satisfaction, marital communication, marital conflict resolution, and marital stability have also affected married individuals' marital satisfaction. A longitudinal study that has been administered with 283 married couples and assessed the relationship between sexual satisfaction, relationship quality, and relationship instability [28]. The authors demonstrated that higher sexual satisfaction resulted in the improvement of relationship quality in terms of happiness and satisfaction. Other researches have also revealed that there was a positive relationship between marital satisfaction and marital stability [29].

Couples' communication is a very important and fundamental factor in understanding the couple's satisfying relationship [30], and which determines couples' conflict resolution abilities. Different studies reveal that in marital relationships hostile or demanding communication behavior leads towards conflict and then to relationship dissatisfaction [31]. The essential to success in marriage is how couples handle their conflicts and differences. Kurdek [32] has found that each spouse's marital satisfaction is positively associated with the frequency with which each spouse uses constructive strategies to resolve conflicts, such as agreement, compromise, and humor.

Like in most of the continents and countries of the world marital breakdown is also growing in Ethiopia and Addis Ababa in particular. Data obtained from Addis Ababa City Administration Vital Events and Residents Service indicates that the relationship between couples is becoming fragile, and marriage breakdown is alarmingly increasing. If contributing factors to making or breaking the couple's relationships are not investigated and reported to stakeholders, the subsequent effect of marriage breakdown will continue hampering families and communities in general and younger children of the divorced parents in particular. To this end, this paper contributes to the expansion of research on marital satisfaction into non-Western contexts by exploring the determinants of marital satisfaction in Ethiopia. The expansion of research into non-Western contexts provides the following new opportunities. First, it presents an opportunity to examine how aspects of marital relationship 
variables that are not common in Western contexts influence marital satisfaction. For example, a study from Cameroon examines how polygamy shapes marital satisfaction [33]. Similarly, studies from China examine how participation in the choice of one's spouse and parent's approval of spouses shapes the experience of marital satisfaction [34, 35]. Second, the expansion into non-Western contexts provides the opportunity to examine how universal determinants of marital satisfaction play out differently or similarly in other contexts. Therefore, based on the literature review it had been hypothesized that sexual relationships, marital stability, marital communication, marital conflict resolution, and socio-demographic variables could predict marital satisfaction.

\section{Conceptual Framework}

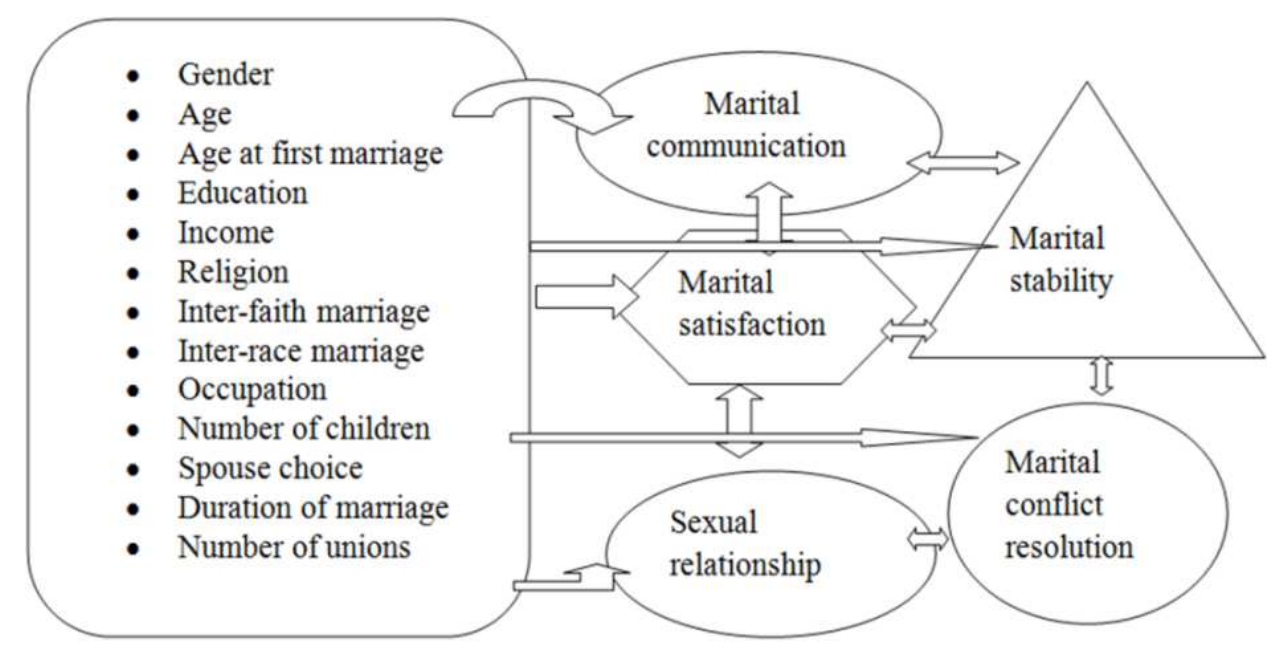

Figure 1. Conceptual framework showing associations among socio-demographic and other marital satisfaction factors.

\section{Research Methodology}

\subsection{Participants}

The target population for this study was all heterosexual married individuals, legally bound by the state of marriage as husband and wife and who were living in Nifas Silk Lafto Sub City, Addis Ababa, Ethiopia. For drawing the samples for the actual research three Werdas were selected out of the total Weredas of the sub-city. These were Woreda Two, Four, and Seven. In these three Woredas, there were 1700 households. Out of these households, 326 households were randomly selected. The total households were obtained from each Werda's administration office together with the identification number of the houses. The researcher has collected data from one of the partners rather than from both of them. The participants were in committed marriage relationships for at least six months and no single-parent or cohabiting parent families were surveyed.

\subsection{Sampling Techniques}

For this study, a systematic sampling technique along with simple random sampling techniques was employed to select the study units. First, out of the total Woredas, three Woredas were selected randomly using the lottery method. Second, from the chosen Woredas, 326, which is computed using a formula to estimate two population mean, households were selected systematically. The sampling interval was found to be every $5^{\text {th }}$ house, which was calculated by dividing the sampling frame (1700) by the required sample size (326).
The units (households) listed in the frame were numbered in a sequence, starting with one as the first item at the head of the list and continuing down to the last item according to their physical proximate. To determine the first $N^{\text {th }}$, the lottery method was used (i.e., to identify the first house number). In the case where there was no eligible person in the selected household, the data collector would go to the next selected household until he/she got an eligible respondent.

\subsection{Study Variables}

Marital satisfaction was the dependent variable of this study. The independent variables were: age, gender, ethnicity, age at first marriage, number of children, level of education, occupation, income, number of marriages/unions, length of the marriage, type of marriage (inter-racial or not, and interfaith or not, arranged or love), sexual relationship, marital stability, marital communication, and marital conflict resolution.

\subsection{Data Collection Instruments}

The tools of data collection comprised of a demographic questionnaire and five Likert type instruments. The selfreport Likert-type questionnaires were adapted and used to measure five constructs: (a) the marital satisfaction, (b) marital stability, (c) sexual relationship, (d) marital communication, and (e) marital conflict resolution. Most of the five self-report Likert-type measures have been employed in the previous study and all of the instruments have 
displayed good psychometric properties.

Revised Dyadic Adjustment Scale (RDAS) As a Measure of Marital Satisfaction. The Revised Dyadic Adjustment Scale (RDAS) is a 14-item revised version of the original Dyadic Adjustment Scale designed to measure marital satisfaction [36]. The revised version offers improved psychometric properties, is shorter, and includes only three of the original four subscales [37]. The RDAS yields a Total Adjustment Score (maximum $=69$ and minimum $=0$ ). Points on the RDAS range from 0 to 69 with higher points indicating greater marital satisfaction and lower scores indicating greater marital distress. Crane, D. R., Middleton, K. C., \& Bean, R. A. [38] reported that the RDAS has been found to have a Cronbach's alpha (reliability) of .90 .

Marital Status Inventory (MSI) As a Measure of Marital Stability: Marital Status Inventory scores were used as the measurement of the dependent variable "marital stability." The MSI is a 14-item, self-administered, true-false, Guttmantype scale that assesses the dissolution potential of marital relationships [39]. The split-half reliability is .86 [40]. Scores range from 0 to 14 with higher scores indicating greater marriage instability. In this study, the MSI scores were reversed to obtain the direction that was consistent with that of other variables. Higher reversed scores indicate higher marital stability and lower scores indicate lower marital stability.

ENRICH Marital Inventory. To measure married individuals' sexual relationship, marital communication, and marital conflict resolution, the Evaluation and Nurturing Relationship Issues, Communication, and Happiness (ENRICH) Inventory was used. The ENRICH Inventory contains 125 items in 14 scales [41].

ENRICH Sexual Relationship Scale. The 10-item sexual relationship scale examines the partner's feelings about the affectional and sexual relationship. Items of this sub-scale reveal attitudes about sexual issues, sexual behavior, birth control, and sexual fidelity. Also included in this dimension is the amount of affection in the relationship and the ability to communicate about sexual issues. Lower levels of satisfaction in the sexual relationship and disagreement concerning any of the aforementioned topics lead to lower scores within this category. In contrast, an agreement concerning affection and attitudes surrounding sex are not only associated with higher satisfaction but also high scores within this dimension.

ENRICH Marital Communication Scale. This is a 10-item measure of couple communication that has been widely used in the general population [42]. It is concerned with an individual's feelings and attitudes toward communication in his or her relationship. This scale not only reflects the partner's attitudes but also allows individuals to discuss the differences in their styles of communication. Higher scores within this dimension suggest that a couple can express their feelings and also feel heard by their partner. Conversely, couples with a lower level of satisfaction and differences in their communication styles have lower communication scores. The scale had an internal consistency reliability of .82 and test-retest reliability of .90 in a sample of 7, 261 couples [42].

ENRICH Marital Conflict Resolution Scale. This scale assesses the partner's perception of the existence and resolution of the conflict in the relationship. Items focus on the openness of partners to recognize and resolve issues and the strategies used to end arguments. The purpose of this scale is twofold. First, the items within this scale measure the couple's ability to determine if a conflict exists within the relationship. Additionally, this scale also assesses the couple's ability to resolve conflict effectively by focusing on the strategies used to end arguments as well as their willingness to recognize and confront conflict.

Couples who struggle with the ability to resolve conflict or avoid all aspects of conflict receive lower scores within this scale. In contrast, couples with higher scores in the conflict resolution scale are more satisfied with the process by which conflicts are handled and also have realistic views regarding the role of conflicts within the marital relationship. This scale had an internal consistency reliability of .84 and test-retest reliability of .90 in a sample of 7,261 couples [42].

\subsection{Pilot Testing}

Before conducting the pilot test, the background questionnaire, the five standardized instruments were translated from the original English language to Amharic by the researcher and one colleague of the researcher. Each Amharic version was then translated back to English by two English Literature graduate students who were fluent in English and Amharic. The back-translated of the Amharic version and the original English version were compared, reviewed for cultural meaning and discrepancies in wording. In the current study, the pilot test was conducted mainly to test the internal reliability of the five Amharic version standardized scales. In addition to testing the reliability of standardized scales, the pilot data were used to assess the appropriateness of the proposed data analysis techniques and to determine if the research questions are formulated in concrete, measurable terms, to get insights for establishing appropriate design and procedures for the main study i.e., to check the appropriateness of instruments and overall procedures as well as to make the necessary revisions (if any) before they were used in the main study.

In the present study, the Amharic version of the instrument was administered to 42 married individuals of which 20 were male and 22 were female. Participants for the pilot test were selected through convenience from different target population from which the sample for the main study was not selected to avoid contamination of information. The tools of data collection were administered to pilot participants in the same way as they would be administered in the main study. In the pilot survey, after obtaining verbal informed consent, participants were asked to complete the Amharic versions of a demographic profile and the five scales.

Internal Consistency Reliability of the Scale Instruments. As a measure of reliability, the internal consistency of the items of the five Amharic versions scales was examined by 
computing Cronbach's alpha. Cronbach's alpha provides a measure of the extent to which the items on a scale provide consistent information concerning each individual's level of the trait of interest. Cronbach's alpha ranges from 0 to 1.00 , with values near to 1.00 showing high internal consistency. George and Mallery [43] provide the following rules of thumb: " $>.90$ - Excellent; at the level of the best-standardized tests,.80-.90 - Good, ..70 - .80 - Acceptable; There are probably a few items that could be improved, >.60-.70 Questionable, this test needs to be supplemented by other measures and there are probably some items which could be improved, and >.50-.60 - Poor, and <.50 - Unacceptable".

Table 1. Mean, Standard deviation and Alpha Coefficients of RDAS, MSI, ENRICH Sexual relationship, ENRICH Marital Communication Scale, and ENRICH Marital Conflict Resolution for the Pilot Test $(N=42)$.

\begin{tabular}{|c|c|c|c|c|c|c|}
\hline Scales & No. of Items & $M$ & $S D$ & $\boldsymbol{\alpha}$ & $\alpha$ during the Main Study & Remark Based on $\alpha$ \\
\hline RDAS & 14 & 54.55 & 9.68 & .82 & .91 & Good \\
\hline MSI & 14 & 12.40 & 2.60 & .86 & .92 & Good \\
\hline Sexual Relationship & 10 & 40.13 & 5.19 & .71 & .73 & Acceptable \\
\hline Communication & 10 & 37.86 & 5.14 & .72 & .78 & Acceptable \\
\hline Conflict Resolution & 10 & 36.67 & 8.10 & .74 & .80 & Acceptable \\
\hline
\end{tabular}

$\mathrm{M}=$ mean, $\mathrm{SD}=$ standard deviation, $\alpha=$ Cronbach's alpha

The result of the pilot test from the alpha tests indicates that there was a consistency to the items measuring each construct and all the constructs are deemed acceptable as each of the Alpha value is ranged from 0.71 to .86, which is within the acceptable range of internal consistency for an Alpha Reliabilities of the scales. As Table 1 shows, the reliability of the variables for the main study $(\mathrm{N}=308)$ ranged from .73 (sexual relationship) to .92 (marital stability), which satisfied the required minimum level of reliability.

Item-Total Correlation. Item total correlations of all the five scales were computed to analyze each item to check whether all items significantly measured their respective constructs. This suggested that each scale item was individually correlated with the total score of their corresponding scale for internal consistency. In computing item-total correlation there is two most important measure of internal consistency. These are Corrected item-total Correlation and Alpha if Item Deleted. Corrected item-total correlation shows the correlation between scores on each item and the total scale scores; according to many kinds of literature, an acceptable corrected item-total correlation should be $>.3$ [44]. Whereas Alpha if Item Deleted shows how the alpha for the scale would change if the item was deleted from the scale if eliminating an item would substantially increase alpha, then you should consider removing the item from your scale.

Table 2. Mean, Standard Deviation, and Item-Total Correlations of Each Item of the Five Scales for the Pilot Test (N=42).

\begin{tabular}{|c|c|c|c|c|c|c|c|c|c|c|}
\hline \multirow{2}{*}{ Items } & \multicolumn{5}{|c|}{ Corrected Item-Total Correlation } & \multicolumn{5}{|c|}{ Cronbach's Alpha if Item Deleted } \\
\hline & RDAS & MSI & SR & MC & MCR & RDAS & MSI & SR & MC & MCR \\
\hline 1 & .553 & .335 & .405 & .323 & .309 & .809 & .876 & .708 & .619 & .745 \\
\hline 2 & .519 & .680 & .375 & .301 & .527 & .809 & .847 & .696 & .585 & .693 \\
\hline 3 & .610 & .480 & .526 & .298 & .510 & .801 & .861 & .726 & .653 & .703 \\
\hline 4 & .561 & .538 & .777 & .248 & .637 & .807 & .854 & .583 & .624 & .683 \\
\hline 5 & .647 & .709 & .244 & .305 & .395 & .799 & .847 & .614 & .685 & .716 \\
\hline 6 & .502 & .491 & .410 & .349 & .384 & .809 & .858 & .676 & .577 & .730 \\
\hline 8 & .466 & .586 & .767 & .512 & .367 & .813 & .853 & .613 & .703 & .719 \\
\hline 9 & .180 & .627 & .536 & .487 & .516 & .828 & .851 & .652 & .624 & .695 \\
\hline 10 & .537 & .457 & .349 & .534 & .273 & .809 & .860 & .70 & .705 & .751 \\
\hline 11 & .237 & .683 & & & & .826 & .851 & & & \\
\hline 12 & .413 & .476 & & & & .818 & .860 & & & \\
\hline 13 & .444 & .721 & & & & .817 & .854 & & & \\
\hline 14 & .479 & .721 & & & & .812 & .854 & & & \\
\hline
\end{tabular}

SR (sexual relationship), MC (marital communication), MCR (marital conflict resolution)

As Table 2 reveals that all items from all scale appeared to be worthy of retention even if item 9 and 11, of RDAS, item 5 of ENRICH SRS, item 3 and 4 of ENRICH MC and item 10 of ENRICH MCR have below the required coefficient level of corrected item-total correlation. Using the Cronbach's alpha if item deleted information, removing items 9 and 11 of RDAS resulted in an increase in Cronbach's alpha from .82 to .828 and .826 , respectively, and item 10 of ENRICH MCR increased alpha from .74 to .751. However, item number 3 and 4 of the ENRICH Sexual Relation Scale did not change Cronbach's alpha to increase. To sum up, the reliability results of the pilot test, all the Amharic versions of this scale have good reliability tests to use with some revision and correction.

\subsection{Data Processing and Analysis}

Data were screened before performing any statistical analysis; the collected data were sorted, validated, and organized for analyzing using Statistical Package for Social Sciences (SPSS) widow version 20. Both descriptive and inferential statistics were used. Descriptive statistics like reliability, mean, standard deviations, frequency and 
percentage, skewness, kurtosis, and tables and figures were conducted. To determine the predictors of marital satisfaction a hierarchical multiple linear regression analysis was conducted. Before analyzing to test the hypothesis, the data were examined for its linearity, normality, and outliers and other assumptions. As conventional, a $p \leq .05$ will be used to indicate statistical significance.

\subsection{Ethical Clearances}

Making ethical considerations is imperative due to the sensitive and personal nature of the study. Hence, ethical approval and clearance were obtained from the Institutional Review Board of the School of Psychology, Addis Ababa University. Written permission was obtained from Nifas Silk Lafto Sub-City Administration to carry out the study among married individuals who were living in the sub-city during the study period. The participants were made fully aware of the content and purpose of the research and only willing participants were included in the study. Participants were informed that the information they offer would be confidential and would not be used other than academic purposes.

\section{Results}

\subsection{Screening the Data for Assumptions Prior to the Main Analysis}

Although 326 questionnaires were distributed to study participants, 308 completed copies of the questionnaires were returned and made the response rate to be $94.5 \%$, and all of these were appropriate for any statistical analysis. Out of the total respondents in this study, $178(57.8 \%)$ were females and 130 were males (42.2\%). Before testing the hypotheses, variables were examined for accuracy of data entry, missing values, and fit between their distributions and the assumptions of univariate, bivariate, and multivariate statistics, namely outliers, skewness, kurtosis, normality, linearity, multicollinearity, homogeneity of errors (homoscedasticity), and normality of errors.

The overall count of missing values per variable for a case was less than $10 \%$. Each of the missed data was replaced by mean imputation systems. With regard to outliers, the researcher used many techniques to rule out or make corrections of both univariate and multivariate outliers. To detect univariate outliers standardized scores ( $>$ \pm 3 , considered as outlier score), kurtosis and skewness were used. In the current data, there were some outliers. Outliers on the negative side (scores, <-3) were changed to the nearest lowest non-outlier scores whereas in the positive side (scores, $>+3$ ) the outliers changed to the highest near non-outlier points. In the case of multivariate outliers, Cooks' Distance (absolute values greater than 1 is a cause for concern) and Leverage (cutoff point, greater than .5 is caused for concerns) were used. In any analyses for testing the current hypotheses, there was no data above the cutoff points of the two multivariate outlier detection techniques.

Both univariate and multivariate normality of the continuous independent and dependent variables were examined. To carry out this assumption the researcher carried out skewness, kurtosis, histogram, Q-Q plot charts and box plots. Using these techniques the data were not enough to violate the normality assumption. In addition to the normality of variables, all the relationships in this study were examined for linearity. Linearity was assessed by examining the scatter plots of the variables. Almost all the scatter plots followed a linear pattern. Multicollinearity among variables was examined before conducting the multiple regression analysis using tolerance levels and variance inflation factor (VIF) values. Multicollinearity in regression models occurs due to the unacceptably high level of inter-correlation among the independent variables, a correlation coefficient $(r \geq .85)$ indicating multicollinearity or variables measuring the same thing [45]. Tolerance measures the influence of one independent variable on all other independent variables. Tolerance levels for correlations range from zero (no independence) to one (completely independent) [46]. The VIF is an index of the amount that the variance of each regression coefficient is increased over that with uncorrelated independent variables [46]. When a predictor variable has a strong linear association with other predictor variables, the associated VIF is large and is evidence of multicollinearity [47]. Thus, very small tolerance values denote high collinearity. A tolerance value of less than .10 or VIF greater than 10 indicates multicollinearity [46]. If the tolerance value is less than some cutoff value, usually the independent variable should be dropped from the analysis due to multicollinearity [48].

The other multiple linear regression analysis assumptions that were checked in this study were homoscedasticity. The assumption of homoscedasticity refers to the equal variance of errors across all levels of the independent variables [49]. This means that researchers assume that errors are spread out consistently between the variables [46]. This is evident when the variance around the regression line is the same for all values of the predictor variable. Homoscedasticity was checked by the visual examination of scatter plots of the standardized residuals by the regression standardized predicted value. In the current study, nearly all residuals were randomly scattered around zero (the horizontal line) providing even distribution. Finally, the residuals (errors) are approximately normally distributed. To check this assumption a histogram (with a superimposed normal curve) and a Normal P-P Plot was used.

\subsection{Descriptive Statistics for the Study Variables}

As a second step in the analysis means, standard deviations, kurtosis, skewness, and correlations of the variables (i.e., marital satisfaction, marital stability, sexual relationship, marital communication, and marital conflict resolution) were computed. The results are presented in Tables $3 \& 4$. 
Table 3. Summary of Means, Standard Deviations, Kurtosis, and Skewness for the Main Study Variables ( $N=308)$.

\begin{tabular}{lllll}
\hline Variables & $\boldsymbol{M}$ & $\boldsymbol{S D}$ & Kurtosis & Skewness \\
\hline Marital satisfaction & 52.01 & 13.74 & -1.13 & .48 \\
Martial stability & 11.14 & 3.55 & -1.33 & .78 \\
Sexual relationship & 38.70 & 7.53 & -.74 & .35 \\
Marital communication & 36.15 & 6.40 & -.24 & -.44 \\
Marital conflict resolution & 35.19 & 8.73 & -.14 & -.95 \\
\hline
\end{tabular}

Note. 'M' denotes mean, SD (standard deviation)

Table 3 presents the means, standard deviations, skewness, and kurtosis of the main continuous variables for the total sample of married individuals. All of the absolute values of skewness were lower than one and those of the kurtosis were all lower than three (i.e., ranged from -1.33 to -.14) which showed that all the continuous main variables were almost univariately normally distributed [48]. In the current study
RDAS which has zero as the minimum score and 69 as the maximum raw score per individual were used to measure the marital satisfaction of married individuals. As Table 3 presents, it was found that married individuals had an average score of $52.01(S D=13.74)$ marital satisfaction. The marital stability of the current participants was measured using MSI, which has 14 true-false questions and its score ranged from 0 to 14 . In the current study, the mean point of marital stability using MSI was $11.14 \quad(S D=3.55)$. Participants' sexual relationship, marital communication, and marital conflict resolution were measured using ENRICH Marital Inventory. Each of these scales has 10 items with a five-point scale and the score ranges from 10 to 50 points per person. Study participants' sexual relationship, marital communication, and marital conflict resolution mean scores were $38.70(S D=7.53), 36.15(S D=6.40)$, and 35.19 $(S D=8.73)$, respectively.

Table 4. The Zero-order Correlations among measured variables for all Study Samples $(N=308)$.

\begin{tabular}{|c|c|c|c|c|c|c|c|c|c|}
\hline Variables & 1 & 2 & 3 & 4 & 5 & 6 & 7 & 8 & 9 \\
\hline Age & - & $.23^{* *}$ & $.76^{* *}$ & $.30^{* *}$ & $-.14^{*}$ & -.05 & .01 & -.12 & -.07 \\
\hline Income & - & & $.14^{*}$ & $.23^{* *}$ & .01 & -.03 & .07 & -.03 & -.03 \\
\hline Marriage du & & & - & $-.24^{* *}$ & -.07 & -.07 & .10 & -.03 & -.04 \\
\hline Age at first marriage & & & & & .07 & $.16^{* *}$ & .05 & .05 & $.13^{*}$ \\
\hline Marital.S & & & & & & $.68^{* *}$ & $.70^{* *}$ & $.67^{* *}$ & $.69^{* *}$ \\
\hline Marital stability & & & & & & - & $.58^{* *}$ & $.55^{* *}$ & $.57^{* *}$ \\
\hline Sexual.R & & & & & & & & $.64^{* *}$ & $.66^{* *}$ \\
\hline Marital.C & & & & & & & & & $.70^{* *}$ \\
\hline Marital.CR & & & & & & & & & \\
\hline
\end{tabular}

Note. * Significant at $p<.05, * * p<.01$ (2-tailed). du, duration), Marital. S (marital satisfaction), Sexual. R (sexual relationship), Marital. C (marital communication) and Marital. CR (marital conflict resolution)

Table 4 shows the correlation matrix of the married individuals' for the investigated variables including continuous socio-demographic variables. The results indicated that marital satisfaction was not significantly correlated with income, marriage duration, and age at first marriage, but it was negatively and significantly correlated with married individuals' age $(r=-.14, p<.05)$. Marital satisfaction was strongly, positively and significantly correlated with marital stability $(r=.68, p<.01)$. Marital satisfaction is also strongly and negatively and significantly associated with a sexual relationship, marital communication and marital conflict resolution ( $r=.70, r=.67$ and $r=.69$, respectively, $p<.01)$. Marital stability was positively and significantly correlated with a sexual relationship, marital communication and marital conflict resolution $(r=.58, r=.55$ and $r=.57$, respectively, $p<.01)$. The sexual relationship had a positive and significant association with marital communication and marital conflict resolution $(r=.64$ and $r=.66$, respectively, $p<.01)$. Marital communication did not correlate with married individuals' age, income, and duration of the marriage, but it had a positive relationship with age at first marriage $(r=.13, p<.05)$. Marital communication was correlated strongly, positively and significantly with marital conflict resolution $(r=.70, p<.01)$.

Hypothesis. Marital stability, sexual relationship, marital communication, marital conflict resolution, and sociodemographic variables could predict marital satisfaction. To identify predictors of marital satisfaction a hierarchical multiple linear regression analysis was performed. To select candidate explanatory variables before analyzing the multiple linear regression, a series of a one way-ANOVA, Person correlation, and independent $t$-test for preliminary analyses were conducted between socio-demographic variables (age, gender, and ethnicity, age at first marriage, number of marriages/unions, length of the marriage, type of marriage (inter-race marriage or not, and interfaith or not), number of children, level of education, occupation, and level of income) and marital satisfaction (i.e., the criterion variable).

A significant positive correlation was found between age and marital satisfaction, $r=-.14, p<.05$. The one wayANOVA test showed that there was a statistically significant difference in the mean score of marital satisfaction for the different occupation types, $F(3,304)=6.35, P=.001$. A twosample independent $t$-test showed that many marriages/unions had a significant association with marital satisfaction. Married individuals who were in their first marriage had greater marital satisfaction scores than married individuals who were in their second marriage, $t(306)=$, $3.03 p=.003$, with means $(S D)$ of 52.92 (13.07) and 45.43 (16.30), respectively. An independent group $t$-test was conducted between those whose marriage type was arranged and those whose marriage type was love, with marital satisfaction as the dependent variable. The test revealed that a much lower level of marital satisfaction for those whose marriage type was arranged $(M=43.14, S D=14.76)$ than 
married individuals whose marriage type was love $(M=53.94$, $S D=12.65), t(306)=-5.45, p=.001$. In the preliminary analysis, other than age, occupation, a number of unions and choice of marriage none of the remaining analyses were significant. In addition to the socio-demographic variables, marital stability, sexual relationship, marital communication, and marital conflict resolution were significantly correlated with marital satisfaction in the Pearson bivariate correlation. Variables that were only significant in the preliminary analysis entered in the multiple regression models.

Table 5. Summary of Hierarchical Multiple Linear Regression Analyses for Variables Predicting Marital Satisfaction (N=307).

\begin{tabular}{|c|c|c|c|c|c|c|c|c|c|c|}
\hline \multirow{2}{*}{ Predictors } & \multicolumn{2}{|l|}{ Stage 1} & \multicolumn{2}{|l|}{ Stage 2} & \multicolumn{2}{|l|}{ Stage 3} & \multicolumn{2}{|l|}{ Stage 4} & \multicolumn{2}{|l|}{ Stage 5} \\
\hline & B & $\beta$ & B & $\beta$ & $B$ & $\beta$ & B & $\beta$ & B & $\beta$ \\
\hline Constant & $43.83 *$ & & 1.35 & & 5.68 & & 5.19 & & -2.11 & \\
\hline Age & -.13 & -.08 & -.17 & $-.10 * *$ & -.17 & $-.10 * *$ & -.16 & $-.09 * *$ & -.13 & $-.08 *$ \\
\hline Housewf & 16.85 & $.27 * * *$ & 9.98 & $.16^{* *}$ & 3.68 & .06 & 2.06 & .03 & 1.92 & .03 \\
\hline Laborer & 15.76 & $.19 * * *$ & 9.69 & $.12 * *$ & 5.43 & .07 & 5.11 & .06 & 7.37 & $.09 *$ \\
\hline Employed & 10.11 & $.29 * * *$ & 6.25 & $.18 * *$ & 2.41 & $.07 *$ & .58 & .02 & .83 & .02 \\
\hline $2^{\text {nd }}$ union & -8.39 & $-.19 * *$ & -4.58 & $-.10 *$ & -3.24 & $-.07 *$ & -3.1 & $-.07 *$ & -2.64 & -.06 \\
\hline Love ma & 9.35 & $.26 * * *$ & 4.40 & $.12 * *$ & 2.79 & $.08 *$ & 1.87 & .05 & 1.73 & .05 \\
\hline SR & & & 1.22 & $.67 * * *$ & .87 & $.48 * * *$ & .59 & $.33 * * *$ & .51 & $.28 * * *$ \\
\hline MS & & & & & 1.40 & $.36 * * *$ & 1.14 & $.29 * * *$ & 1.04 & $.27 * * *$ \\
\hline MCR & & & & & & & .47 & $.31 * * *$ & .35 & $.22 * * *$ \\
\hline $\mathrm{MC}$ & & & & & & & & & .39 & $.18 * * *$ \\
\hline$R$ & .46 & & .78 & & .83 & & .85 & & .86 & \\
\hline$R^{2}$ & .21 & & .61 & & .68 & & .73 & & .74 & \\
\hline$\Delta R^{2}$ & $\underline{-}$ & & .40 & & .07 & & .04 & & .01 & \\
\hline$F$ & $\overline{5.60} * * *$ & & $30.78 * * *$ & & $39.77 * * *$ & & $45.39 * * *$ & & $45.83 * * *$ & \\
\hline$\Delta F$ & & & $302.43 * * *$ & & $68.27 * * *$ & & $43.19 * * *$ & & $15.24 * * *$ & \\
\hline
\end{tabular}

Note. Housewf denotes Housewife, love ma (love marriage), SR (sexual relationship), MS (marital stability), MCR (marital conflict resolution), and MC (marital communication)

$*$ Denotes significant at $p<.05, * * p<.01, * * * p<.001$ (2-tailed).

A hierarchical multiple linear regression analysis was conducted to identify predictors of marital satisfaction among married individuals. Categorical variables were entered into the analyses as dummy variables (e.g., participant's occupation was recorded as, laborer $=0$ (reference category), and housewife, merchant, and employed as =1). Sociodemographic variables were entered using the forced entry in the first block, followed by a forward stepwise entry of sexual relationship, marital stability, marital conflict resolution, and marital communication scores.

As Table 5 reveals that at stage one, socio-demographic variables were entered simultaneously. They contributed significantly to the regression model, $F(6,301)=5.60$, $p<.001)$ by explaining $21 \%$ of the variance in marital satisfaction among married individuals. In this model except for age $(b=-.13, \beta=-.08, p>.05)$ all the six sociodemographic variables were found to be significant at the alpha level, $p<.001$. While introducing sexual relationships in the second stage of the regression model it made a significant contribution by adding $40 \%$ of explained variance in marital satisfaction, $\Delta F(1,300)=302,43, p<.001$. Controlling for the socio-demographic predictors, the sexual relationship was significantly predicted and positively correlated with marital satisfaction $(b=1.22, \beta=.67, p<.001)$. In this stage all of the socio-demographic predictors significantly contributed for the model, $R^{2}=.61, F(7,300)=30.78, p<.001$ : age $(b=-.17$, $\beta=-.10, p<.01)$, housewife $(\mathrm{b}=9.98, \beta=.16, \mathrm{p}<.01)$, laborer $(b=9.69, \beta=.12, p<.01)$, employed $(\mathrm{b}=6.25, \beta=.18, \mathrm{P}<.01)$, second union $(b=-4.58, \beta=-.10, \mathrm{P}<. .05)$, and love marriage $(b=4.40, \beta=.12, p<.01)$.

In stage 3 marital stability $(b=1.40, \beta=.36, p<.001)$ made a valuable but relatively low contribution $(\Delta F(1,299)=$
$68.28, p<.001)$ by adding $7 \%$ of explained variance in marital satisfaction. In this stage except for housewife and laborer type of occupations all other variables were significantly contributed to the model, $R^{2}=.68, F(8,299)$ $=39.77, p<.001$. In stage 4 the addition of marital conflict resolution $(b=.47, \beta=.31, p<.001)$ to the regression model increased $R^{2}$ by $4 \%$, with other variables held constant, $\Delta F$ $(1,298)=43.19, p<.001$. Only age $(b=-.16, \beta=-.09, p<.01)$ and second union $(b=-3.1, \beta=-.07, p<.05)$ of sociodemographic characteristics of married individuals were significant at this stage. In this fourth stage marital stability, sexual relationship, marital communication and marital conflict solution contributed significantly to the prediction of married individuals' marital satisfaction at $p<.001$.

Finally, in stage 5 adding marital communication to the model accounted for only $1 \%$ of the variance in marital satisfaction, but the change in $R^{2}$ was statistically significant, $\Delta F(1,297)=15.24, p<.001$. In the final model from the socio-demographic variables only age and laborer types of occupation predicted significantly married individuals' marital satisfaction, $b=-.13, \beta=-.08$, and $b=7.37, \beta=.09$, respectively, $p<.05$. This means that for every one-unit increase in age, predicted marital satisfaction scores decrease by .13 , with other variables held constant. Similarly, on average, predicted marital satisfaction scores for laborers were 7.37 points higher than for merchants (i.e., reference category), with other variables held constant. In this final stage sexual relationship, marital stability, marital conflict resolution, and marital communication were significant predictors of marital satisfaction, with other variables held 
constant, at $p<.001$. The most important predictors of marital satisfaction in this regressions model were sexual relationships followed by marital stability $(b=.51, \beta=.28$, and $b=1.04, \beta=.27$, respectively, $p<.001)$. Together all the significant independent variables in this final stage accounted for $74 \%$ of the variance in married individuals' marital satisfaction and the model was significant, $F(10,297)$ $=45.83, p<.001$.

\section{Discussions}

The primary focus of this study was identifying predictors of marital satisfaction of married individuals. It was predicted that marital stability, sexual relationship, marital communication, marital conflict resolution, and sociodemographic variables could predict marital satisfaction. Hierarchal multiple linear regressions were used to explain which variables account for the most variance in the presence of the other variables. In this regression analysis from the socio-demographic variables, only laborer types of occupation and age predicted significantly married individuals' marital satisfaction. On average, predicted marital satisfaction scores for laborers were higher than for merchants. Even if I recommend further research on this issue, there is a strong common belief in our country that is love is better among poor people than reach people.

The result suggests that age has a negative association with marital satisfaction meaning that older individuals gain less satisfaction from their marriage. This result is consistent with a study conducted by Jose and Alfons [7] who found that age has a negative impact on marital satisfaction. On the contrary, Argyle and Furnham [24] have asserted that older individuals tend to report greater satisfaction from their relationships. Possible explanations for this decline in marital satisfaction among married individuals is may be due to an increase in couples' responsibilities, the presence of children and financial problems associated with raising children. Moreover, specifically in our culture, when age increases husbands become looking outside other girls for having sex, the main reason for this is that wives' beautifulness and attractiveness become decreasing due to lack of self-care as a result of holding the whole responsibility of the household such as looking after the children, feeding the family, engaging in the social interaction, and their belief, I have already married.

Surprisingly by opposing many previous research findings, gender, ethnicity, age at first marriage, number of children, level of education, occupation, income, number of marriages/unions, length of the marriage, type of marriage (inter-racial or not, and inter-faith or not, arranged or love did not predict marital satisfaction. For example, variables such as length of the marriage, education, employment status, number of marriages [7]; gender [7-9], absence/number of children $[7,10]$ are reported by previous researchers as the main socio-demographic variables among other predictors of marital satisfaction. This lack of significance may be due, at least in some cases, to the controlling of the study variables in the statistical analysis. In addition to age and laborer type of occupation of socio-demographic variables the findings also showed that sexual relationships, marital stability, marital conflict resolution, and marital communication were significant predictors of marital satisfaction. Therefore, the hypothesis is partially supported.

Among other variables, the research reveals that sexual satisfaction is the most important predictor of marital satisfaction followed by marital stability. This implies that when spouses are satisfied in their sexual relationship they become satisfied in their marital satisfaction as well. This may due to sex has the power to increase attachments and communications among partners. This result is consistent with a longitudinal study that has been administered with 283 married couples and studied the relationship between sexual satisfaction, relationship satisfaction and relationship instability [28]. The authors demonstrated that higher sexual satisfaction resulted in the improvement of relationship quality in terms of happiness and satisfaction. Researches have demonstrated that there is a positive relationship between marital satisfaction and stability [29]. However, this strong link between marital satisfaction and stability yet may be attenuated by a variety of factors. It is also better to keep in mind that not all stable marriages are happy but still stable. In our culture married individuals still stay together by thinking about their children, disagreements during wealth division, and the cultural rejection of divorce. Two earlier studies $[50,51]$ found that marital dissatisfaction did not adequately predict separation or divorce among couples because many dissatisfied couples stay connected.

Couples' communication is a very important and fundamental factor in understanding the couple's satisfying relationship [30], and which determines couples' conflict resolution abilities. Different studies reveal that in marital relationships hostile or demanding communication behavior leads towards conflict and then to relationship dissatisfaction [31]. Likewise, the current study found that marital communication has a positive and significant role in the marital satisfaction of married individuals. This finding corresponds with a study conducted in Addis Ababa by Girma Deressu and Zewdu Girma [52]. They found that marital communication was observed to have a statistically significant predictor effect on marital satisfaction. it is also supported that marital conflict resolution has a positive role in predicting marital satisfaction of married individuals. This is why; many researchers and practitioners say that the essential to success in marriage is how couples handle their conflicts and differences. The finding is similar to Kurdek [32] who was found that each spouse's marital satisfaction is positively associated with the frequency with which each spouse uses constructive strategies to resolve conflicts, such as agreement, compromise, and humor.

The generalizability of the results is majorly confined to the nature of the study sample. The current study collected data exclusively from one sub-city of Addis Ababa and urban married individuals; therefore, additional research on more diverse samples within Addis Ababa is needed. Due to the 
nature of the study, respondents might not give genuine answers to the questions they were asked since this study touches very sensitive and private or personal issues. For example, in the time of data collection, many respondents said that "why are you talking about sex? it is shame talking about it, 'O' my GOD you are crude'. Another significant limitation of the current study is that it is cross-sectional research design. Cross-sectional research only yields descriptive results. However, a longitudinal research design would provide a better representation of the reciprocal relationship between the study variables and it allows more rigorous testing of causal effects. Therefore, the use of crosssectional data makes it difficult to establish causality. On account of this, future investigations on communication, sexual satisfaction, and marital satisfaction and stability would benefit from the collection of longitudinal data.

\section{Conclusion}

The main purpose of this study was to examine the role of socio-demographic, sexual relationship, marital communication, and marital conflict resolution in marital satisfaction among married individuals. From the sociodemographic variables, only age and occupation types of occupation predicted significantly married individuals' marital satisfaction. The result also showed that sexual relationships, marital stability, marital conflict resolution, and marital communication were significant predictors of marital satisfaction. The most important predictor of marital satisfaction was sexual relationships followed by marital stability. Therefore, the current study adds a sound, contextual and specific knowledge to the existing marriage counseling practices and theories as well to enhance or reduce risk factors for married individuals' marital satisfaction. And it would be great to provide psychoeducation on the above socio-demographic and psychosocial determinants of marital satisfaction for married individuals.

\section{Abbreviations}

ANOVA: Analysis of Variance; ENRICH: Evaluation and Nurturing Relationship Issues, Communication, and Happiness; F: Frequency; M: Mean; MC: Marital Communication; MCR: Marital Conflict Resolution; MS: Marital Satisfaction; MSI: Marital Status Inventory; RDAS: Revised Dyadic Adjustment Scale; SD: Standard Deviation; SPSS: Statistical Package for Social Sciences; SR: Sexual Relationship; VIF: Variance Inflation Factor

\section{Ethics Approval and Consent to Participate}

Ethical approval and clearance were obtained from the Institutional Review Board of the School of Psychology, Addis Ababa University. Written permission was obtained from Nifas Silk Lafto Sub-City Administration to carry out the study among married individuals who were living in the subcity during the study period. Informed verbal consent was sought from all participants before administering the questionnaire and the participants were made fully aware of the content and purpose of the research participants were informed that the information they offer would be confidential and would not be used other than academic purposes.

\section{Consent for Publication}

This part is not applicable because the manuscript contains no person's data in any form (including individual details, images, or videos.

\section{Availability of Data and Material}

The datasets used and/or analyzed during the current study are available from the corresponding author on reasonable request.

\section{Competing Interests}

The author declares that he has no competing interests.

\section{Funding}

Not applicable.

\section{Authors' Contributions}

ZG designed the study, collected the data, analyzed the data, interpreted the data, wrote the manuscript, and reviewed the manuscript. The author read and approved the final manuscript.

\section{Acknowledgements}

Not applicable.

\section{References}

[1] Umberson Debra, Williams Kristi, Powers Daniel A, and Chen Meichu. As Good as It Gets? A Life Course Perspective on Marital Quality. Social Forces. 2005; 84: 493-511. [PMC free article] [PubMed] [Google Scholar].

[2] Fincham, F, \& Beach, S., 2010. Marriage in the new millennium: A decade in review. Journal of Marriage and Family, 72, 630-649.

[3] Campbell, A., Converse, P. E., \& Rodgers, W. L. (1976). The quality of American life: Perceptions, evaluations, and satisfactions. Russell Sage Foundation.

[4] Shek DTL and Cheung CK. Dimensionality of the Chinese Dyadic Adjustment Scale based on confirmatory factor analyses. Social Indicators Research. 2008; 86: 201-212.

[5] Lee, K. S., Ono, H., 2008. Specialization and happiness in marriage: A US-Japan comparison. Social Science Research 37, 1216-1234. 
[6] Brassard, A. Shaver, A., and P. R. Lussier, Y, (2007) Attachment, sexual, experiences, and sexual pressure in Romantic relationships: A Dyadic Approach, personal relationships, 14, 475-493).

[7] Jose, O. \& Alfons, V. (2007). Do demographics affect marital satisfaction? Journal of Sex \& Marital Therapy, 33, 73-85.

[8] Renaud, C., Byers, E. S., \& Pan, S. (1997). Sexual and relationship satisfaction in Mainland China. The Journal of Sex Research, 34, 399-410.

[9] Sprecher, S. (2002). Sexual satisfaction in premarital relationships: Associations with satisfaction, love, commitment, and stability. The Journal of Sex Research, 39, 190-196.

[10] White, L., \& Edwards, J. N. (1990). Emptying the nest and parental well-being: An analysis of national panel data. American Sociological Review, 55, 235-242.

[11] Hsueh, A. C., Morrison, K. R., \& Doss, B. D. (2009). Qualitative report of problems in cohabiting relationships: Comparisons to married and dating relationships. Journal of Family Psychology, 23, 236-246.

[12] Kurdek, L. A., \& Schmitt, J. P. (1986). Relationship quality of partners in heterosexual married, heterosexual cohabiting, and gay and lesbian relationships. Journal of Personality and $\begin{array}{lllll}\text { Social } & \text { Psychology, } & 51 & \text { (4), } & \text { 711-720. }\end{array}$ http://dx.doi.org/10.1037/0022-3514.51.4.711

[13] Fisher, T. D., \& McNulty, J. K. (2008). Neuroticism and marital satisfaction: The mediating role played by the sexual relationship. Journal of Family Psychology, 22, 112-122.

[14] Gattis, K. S., Berns, S., Simpson, L. E., \& Christensen, A. (2004). Birds of a feather or strange birds? Ties among personality dimensions, similarity, and marital quality. Journal of Family Psychology, 18, 564-574.

[15] Reath, R. A., Piercy, F., Hovestadt, A., \& Oliver, M. (1980). Assertion and marital adjustment. Family Relations, 29, 249253.

[16] Clymer, S. R. (2006). The relationship among romantic attachment style, conflict resolution style, and sexual satisfaction. Journal of Couple and Relationship Therapy, 5, 71-89.

[17] Egeci, I. S., \& Gencoz, Tulin. (2006). Factors associated with relationship satisfaction: Importance of communication skills. Contemporary Family Therapy, 28, 383-391.

[18] Lemmens, G. M. D., Buysse, A., Heene, E., Eisler, I. \& Demyttenaere, K. (2007). Marital satisfaction, conflict communication, attachment style, and psychological distress in couples with hospitalized depressed patients. Acta Neuropsychiatrica, 19, 109-117.

[19] Shek, D. T. L. (1994). Psychometric properties of the Chinese version of the Dyadic Adjustment Scale. Psychologia: An International Journal of Psychology in the Orient, 37 (1), 7-17.

[20] Amato, P. R., Johnson, D. R., \& Rogers, S. J. (2003). Continuity and change in marital quality between 1980 and 2000. Journal of Marriage and Family, 65 (1), 1-22. http://dx.doi.org/10.1111/j.1741 3737.2003.00001.x

[21] Basat, Ç. (2004). An exploration of marital satisfaction, locus of control, and self- esteem as predictors of sexual satisfaction. Unpublished Master's Thesis, Middle East
Technical University, Ankara.

[22] Guo, B., \& Huang, J. (2005). Marital and sexual satisfaction in Chinese families: Exploring the moderating effects. Journal of Sex and Marital Therapy, 31, 21-29.

[23] Christenson, O. D., Zabriskie, R. B., Eggett, D. L., \& Freeman, P. A. (2006). Family acculturation, family leisure involvement, and family functioning among MexicanAmericans. Journal of Leisure Research, 38, 475-495.

[24] Argyle, M., \& Furnham, A. (1983). Sources of satisfaction and conflict in long-term relationships. Journal of Marriage and the Family, 45 (3), 481-493. http://dx.doi.org/10.2307/351654

[25] Hill, A. (2008). Predictors of relationship satisfaction: The link between cognitive flexibility, compassionate love, and level of differentiation. Unpublished Doctoral Dissertation, Alliant International University.

[26] Moore, K. A., McCabe, M. P., \& Brink, R. B. (2001). Are married couples happier in their relationships than cohabiting couples? Intimacy and relationship factors. Sexual and Relationship Therapy, 16, 35-46.

[27] Kurdek, L. A. (2005). Gender and marital satisfaction early in marriage: A growth curve approach. Journal of Marriage and Family, 67, 68-74.

[28] Yeh, H., Lorenz, F. O., Wickrama, K. A. S., Conger, R. D., \& Elder, Jr., G. H. (2006). Relationships among sexual satisfaction, marital quality, and marital instability at midlife. Journal of Family Psychology, 20, 339-343.

[29] Gager, C. T., \& Sanchez, L. (2003). Two as one? Couples' perceptions of time spent together, marital quality, and the risk of divorce. Journal of Family Issues, 24 (1), 21-50.

[30] Segrin, C., and Flora, J., 2011. Family communication. Routledge.

[31] Gottman, J. M., \& Notarius, C. I. (2002). Marital research in the 20th century and a research.

[32] Kurdek, L. A. (1995). Predicting change in marital satisfaction from husbands' and wives' conflict resolution styles. Journal of Marriage and the Family, 57, 153-164.

[33] Gwanfogbe, P. N., Schumm, W. R., Smith, M., Furrow, J. L., 1997. Polygyny and marital life satisfaction: An exploratory study from rural Cameroon. Journal of Comparative Family Studies 28, 55-71.

[34] Pimentel, E. F., 2000. Just how do I love thee? Marital relations in urban China. Journal of Marriage and the Family $62,32-47$

[35] Whyte, M. K. (1990). Dating, mating, and marriage. New York: Aldine de Gruyter.

[36] Spanier GB. (1976). Measuring dyadic adjustment - New scales for assessing the quality of marriage and similar dyads. Journal of Marriage and the Family. 38: 15-28. [Ref list].

[37] Busby, D. M., Christensen, C., Crane, D. R., \& Larson, J. H. (1995). A revision of the Dyadic Adjustment Scale for use with distressed and non-distressed couples: Construct hierarchy and multidimensional scales. Journal of Marital and Family Therapy, 21, 289-308.

[38] Crane, D. R., Middleton, K. C., \& Bean, R. A. (2000). Establishing criterion scores for the Kansas Marital Satisfaction Scale and the Revised Dyadic Adjustment Scale. 
[39] Weiss, R. L., \& Cerreto, M. (1980). The Marital Status Inventory: Development of a measure of dissolution potential. American Journal of Family Therapy.

[40] Crane, D. R., \& Mead, D. E. (1980). The Marital Status Inventory: Some preliminary data on an instrument to measure marital dissolution potential. The American Journal of Family Therapy, 8 (3). New York: Brunner/Mazel.

[41] Fournier, D. G., Olson, D. H. \& Druckman, J. M. (1983). Assessing marital and premarital relationships: The PREPARE/ENRICH Inventories. In E. E. Filsinger (Ed.), Marriage and family assessment. (pp. 229-250). Newbury, CA: SAGE Publishing.

[42] Fowers, B. J., \& Olson, D. H. (1989). ENRICH Marital Inventory: A Discriminant Validity and Cross-Validity Assessment, 15 (1), 65-79.

[43] George, D., \& Mallery, P. (2003). SPSS for Windows step by step: A simple guide and reference 11.0 update (4th ed.). Boston: Allyn \& Bacon.

[44] Nunnally, J. C., \& Bernstein, I. H. (1994). Psychometric Theory (3rd Ed.). New York, NY: McGraw-Hill.

[45] Garson, D. G. (2007). Path analysis. Retrieved from http://www2.chass.ncsu.edu/garson/pa765/path.htm

[46] Belsley, D. A., Kuh. E., 8: Welsch, RE 1980. Regression diagnostics: Identifying influential data and sources of collinearity.

[47] Cohen, P., West, S. G., and Aiken, L. S., 2014. Applied multiple regression/correlation analysis for the behavioral sciences. Psychology Press.

[48] Hair, J. F., Anderson, R. E., Tatham, R. L., \& Black, W. C. (1998). Multivariate Data Analysis. Upper Saddle River, NJ: Prentice-Hall.

[49] Osborne J., Waters E. (2002). Four assumptions of multiple regressions that researchers should always test. Pract. Assess. Res. $\quad$ Eval. $\quad 8 \quad$ Available at http://PAREonline.net/getvn.asp? $\mathrm{v}=8 \& \mathrm{n}=2$

[50] Gottman, John. (2007). Predicting the Longitudinal Course of Marriages. Journal of Marital and Family Therapy. 17. 3 - 7. 10.1111/j.1752-0606.1991.tb00856.x.

[51] Gottman, J. M., \& Levenson, R. W. (1992). Marital processes are predictive of later dissolution: Behavior, physiology, and health. Journal of Personality and Social Psychology, 63 (2), 221-233. https://doi.org/10.1037/0022-3514.63.2.221

[52] Girma Deressu and Zewdu Girma (2019). The Relationship between Premarital Expectation and Marital Satisfaction among Married Couples in Bole Sub-city of Addis Ababa City Administration. Psychology Research, Vol. 9, No. 10, 387400. doi: 10.17265/2159-5542/2019.10.001. 